\title{
A bridge too many?
}

\author{
From the ${ }^{\mathrm{a}}$ Division of Cardiac Surgery and ${ }^{\mathrm{b}}$ Intensive Care Unit, Heart \& Vascular Institute, Penn State Health \\ Hershey Medical Center, Hershey, Pa. \\ Disclosures: Authors have nothing to disclose with regard to commercial support. \\ Received for publication Nov 13, 2017; accepted for publication Nov 15, 2017; available ahead of print Dec 9, \\ 2017. \\ Address for reprints: John V. Conte, MD, Division of Cardiac Surgery, Heart \& Vascular Institute, Penn State \\ Health Hershey Medical Center, 500 University Drive, Hershey, PA 17033 (E-mail: jconte@ pennstatehealth. \\ psu.edu). \\ J Thorac Cardiovasc Surg 2018;155:1056-7 \\ $0022-5223 / \$ 36.00$ \\ Copyright $(5) 2017$ by The American Association for Thoracic Surgery \\ https://doi.org/10.1016/j.jtcvs.2017.11.059
}

Behzad Soleimani, MD, ${ }^{\mathrm{a}}$ Christoph Brehm, MD, ${ }^{\mathrm{b}}$ David C. Campbell, MD, ${ }^{\mathrm{a}}$ and John V. Conte, MD ${ }^{\mathrm{a}}$
In 1969, Denton Cooley reported implantation of a Liotta total artificial heart in a young woman with postcardiotomy cardiogenic shock followed by orthotopic heart transplant 64 hours later. This "2-staged heart replacement" later became known as bridging to transplantation. For patients presenting with cardiogenic shock, a bridge-to-bridge strategy was later conceived with a short-term assist device followed by longer-term support with a durable device, followed by transplantation. In this issue of the Journal, Pawale and colleagues ${ }^{1}$ challenge the conventional bridge-to bridge approach by implanting a durable device as firstline treatment for selected patients with refractory cardiogenic shock.

The central premise of this paper is that eliminating the bridge-to-bridge step will favorably impact patient outcomes. This argument has support because of limitations of short-term devices. Peripheral extracorporeal membrane oxygenation (ECMO) is associated with lower extremity vascular complications, and incomplete support allows residual left ventricular distension and pulmonary edema. These risks can be largely, but not completely, obviated by distal limb perfusion catheters and left ventricular venting.

The authors report a commendable 74\% 1-year survival in 43 patients with cardiogenic shock treated by primary durable device implantation. One of the arguments against initial durable device implants is the perceived hazard of cannulating a recently infarcted left ventricle. The authors showed this to be safe. In our experience, this risk can be further mitigated by alternate cannulation sites such as inferior left ventricular wall placement of the inflow cannula rather than cannulation of an infarcted apex. When necessary, reoperation for temporary right ventricular support can be avoided by deploying a novel percutaneous right ventricular assist device such as Impella RP (ABIOMED U.S., Danvers, Mass) or TandemHeart Protek Duo (TandemLife, Pittsburgh, Pa). The latter has the advantage of

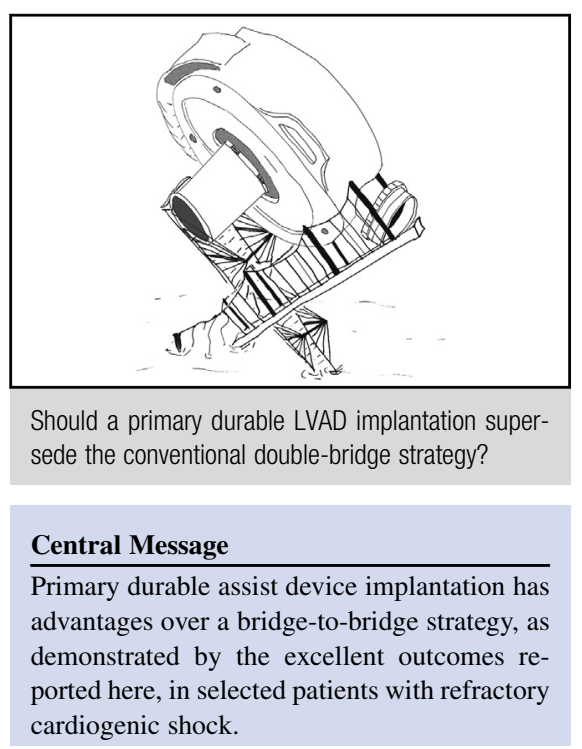

See Article page 1059 available oxygenator support in the event of pulmonary insufficiency.

There are, however, several noteworthy disadvantages to bypassing the bridge-to-bridge step. First, some patients with cardiogenic shock have multiorgan failure that proves irreversible. They are unlikely to survive even with restored circulation regardless of device type. The authors report 4 patients who died in the early postoperative period because of multiorgan failure from preoperative cardiogenic shock. Application of ECMO as bridge-to-bridge would arguably have excluded these patients from a durable device (and the associated costs and resources). A bridge-to-bridge strategy allows assessment of neurologic status in patients who have undergone prolonged cardiopulmonary resuscitation, which should be known before implanting a durable device. Third, and pertinent to patients with acute myocardial infarction and acute myocarditis, some hearts recover and never require long-term support. ECMO support and potential decannulation even when left ventricular function is depressed may permit direct transplantation after aggressive medical support. Fourth, a period of support on a short-term device allows a thorough psychosocial evaluation of a patient's candidacy for a durable device. Because many patients on ECMO can be extubated, they can give informed consent directly, which removes that burden from their families. Finally, during early support on ECMO, the need for either isolated left ventricular support or biventricular support 
with a total artificial heart is better defined. This is particularly relevant when candidacy for transplantation is questionable and a durable device is optimal destination therapy.

\section{Reference}

1. Pawale A, Schwartz Y, Itagaki S, Pinney S, Adams DH, Anyanwu AC. Selective implantation of durable left ventricular assist devices as primary therapy for refractory cardiogenic shock. J Thorac Cardiovasc Surg. 2018;155:1059-68. 